\title{
Naturally Acquired Immunity to Haemophilus influenzae Type B in Healthy Cuban Children
}

\section{Gilda Toraño Peraza+ , Ibis Hernández Vadell, María Eugenia Toledo Romaní, Alberto Baly Gil, Isis Tamargo Martínez, Annia Carmenate García}

\author{
National Reference Center for Haemophilus, Instituto de Medicina Tropical "Pedro Kourí”, Havana, Cuba
}

We have evaluated the prevalence of antibody to immunogenicity of Haemophilus influenzae type $b$ (Hib) in a group of 4 to 5 years old healthy children, who were too old to be included in the first vaccinated cohort when Hib vaccination begun in Cuba in 1999. Serum capsular polysaccharide specific IgG antibody concentrations were measured in 974 healthy children, between February and May 2002. The prevalence of Hib nasopharyngeal carriage was also estimated. The majority of children (99.7\%) had more than $1 \mu \mathrm{g} / \mathrm{ml}$ of antibody. The preliminary report of the nasopharyngeal cultures was positive for $\mathrm{H}$. influenzae in 16 children, but in only one was confirmed as Hib after serotyping (0.1\% Hib nasopharyngeal carrier). These results provide evidence that in Cuba the natural active immunity to Hib can be acquired at an early age.

Key words: Haemophilus influenzae type b - natural immunity - pre-vaccination antibody titres - Cuba

Haemophilus influenzae type b (Hib) disease is now a major cause of vaccine-preventable morbidity and mortality in young children in developing countries. Despite the availability of a protective vaccine, few developing countries are using Hib vaccine in their immunization programs. The major obstacle to the routine use of Hib conjugate vaccine in most non-industrialized countries is cost (Fernández et al. 2000).

In Cuba the Hib vaccination was introduced in the National Immunization Program in 1999, for all the children born between January 1998 and October 1999. After that, the incidence of Hib disease has decreased to 0.1 per 100,000 inhabitants, in 2001 (Dickinson et al. 2001). The purpose of this study was to evaluate the natural acquired immunity to Hib in a group of healthy children 4 to 5 years of age in the last cohort not vaccinated against Hib.

This study was performed between February and May 2002, in the province of Camagüey, Cuba. Nine hundred and seventy four healthy children attending day care centers and schools were selected. No child had previously received Hib vaccine or had received any immunoglobulin preparation or blood product. Demographic and medical data were obtained through a personal interview with the mothers. Blood samples were drawn from children, and the serum was stored at $-20^{\circ} \mathrm{C}$ until further analysis.

Serum capsular polysaccharide specific IgG antibody (anti-PRP) concentrations were measured by a modification of the enzyme-linked immunosorbent assay (ELISA) using HbOHA (NIBSC, Potters Bar, UK) as antigen. A stan-

${ }^{+}$Correponding author. Fax: +53-7-204.6051. E-mail: gilda@ipk.sld.cu

Received 8 April 2004

Accepted 17 September 2004 dard curve was generated by using reference serum (lot 1983 Center for Biological Evaluation and Review, Food and Drug Administration, Bethesda, MD) with a calculated IgG antibody concentration $(60.9 \mu \mathrm{g} / \mathrm{ml})$ (Keythy et al. 1987, Phipps et al. 1990). IgG antibody concentration was logarithmic transformed and the geometric mean concentration (GMC) was calculated.

Nasopharyngeal swabs were collected and inoculated on chocolate agar medium supplemented with $\mathrm{V}$ and $\mathrm{X}$ factor, and incubated in $5 \% \mathrm{CO}_{2}$ in air at $37^{\circ} \mathrm{C}$ overnight. Isolates were identified as $H$. influenzae by their requirements for $\mathrm{V}$ and $\mathrm{X}$ factors (BBL TAXO X and V FACTOR STRIPS, Becton Dickinson Microbiology System). Serotyping of isolated strains was performed by slide agglutination with specific antisera for the capsular types a to $\mathrm{f}$ (Difco Laboratories, Detroit, MI).

The results of anti-PRP specific IgG antibody studied in Cuban children aged 4 to 5 years are shown in the Table. Nine hundred and seventy two children $(99.7 \%)$ had protective level of antibodies. The greatest percentage of children $(59.75 \%$ and $26.07 \%$ ) corresponded to protective titres of antibodies between $1-5 \mu \mathrm{g} / \mathrm{ml}$ and $5 \mu \mathrm{g} / \mathrm{ml}$, respectively. Titres expected to be protective for immediate but short-term periods $(>0.15$ and $<1 \mu \mathrm{g} / \mathrm{ml}$ ) were observed in 136 children (13.96\%). The GMC was 2.71 $\mu \mathrm{g} / \mathrm{ml}$.

The preliminary report of the nasopharyngeal cultures was positive for $H$. influenzae in 16 children, but the identification was confirmed by serotyping in only one culture $(0.1 \%$ Hib nasopharyngeal carrier). The rest of the isolates were noncapsulated, serologically nontypeable H. influenzae.

In the era prior to Hib vaccination in Finland, research has shown that the majority of children 4 to 5 years of age had protective concentrations of antibody. Kaythy et al. $(1991,1992)$ reported that $79 \%$ had titres higher than 0.15 $\mu \mathrm{g} / \mathrm{ml}$ and $32 \%$ had titres greater than $1 \mu \mathrm{g} / \mathrm{ml}$. Similar 
TABLE

Serum capsular polysaccharide specific IgG antibody (antiPRP) titres measured by ELISA in 4-5 years old Cuban children no vaccinated against Haemophilus influenzae b

\begin{tabular}{cccc}
\hline $\begin{array}{c}\text { Anti-PRP } \\
\text { concentration } \\
(\mu \mathrm{g} / \mathrm{ml})\end{array}$ & $\begin{array}{c}\text { Number } \\
\text { of children }\end{array}$ & $\%$ & $\begin{array}{c}\text { GMC } \\
(\mu \mathrm{g} / \mathrm{ml})\end{array}$ \\
\hline$<0.15$ & 2 & 0.20 & \\
$>0.15$ and $<1$ & 136 & 13.96 & $2.71^{a}$ \\
$>1$ and $<5$ & 582 & 59.75 & \\
$>5$ & 254 & 26.07 & \\
\hline
\end{tabular}

GMC: geometric mean concentration of IgG antibody; $a$ : p < 0.05 ; confidence intervals: $2.54-2.78$

findings were noted in India, demonstrating high pre-vaccination anti-PRP titres in over $80 \%$ of children over 4 years of age (Acharya et al. 1997). The GMC in both studies $(0.48 \mu \mathrm{g} / \mathrm{ml}$ in Finland and $0.94 \mu \mathrm{g} / \mathrm{ml}$ in India) was lower than GMC obtained in this research $(2.71 \mu \mathrm{g} / \mathrm{ml})$.

The high pre-vaccination antibody levels in Cuban children suggest that the children had been primed by natural infection. In the pre-vaccine era, most children acquired "natural" immunity by 5-6 years of age through asymptomatic infection by Hib bacteria. Since only a relatively small proportion of children carry Hib at any time, it has been postulated that exposure to organisms that share common antigenic structures with the capsule of Hib (socalled "cross-reacting organisms") may also stimulate the development of anticapsular antibodies against Hib (Bradshaw et al. 1971). For example, biologically active anti-PRP antibodies can be induced by colonization with Escherichia coli K-100, other enteric bacteria, and also Staphylococcus aureus. E. coli are ubiquitous in developing countries like Cuba, and their presence in the gut may have helped to stimulate antibody to Hib (Scheerson et al. 1995, Puliyel et al. 2001).

On the other hand, besides the prevention of invasive infections, Hib conjugate vaccines reduce the oro/nasopharyngeal carriage of Hib because they induce the development of mucosal antibodies than can prevent colonization (Kaythy 1998). The transmission of Hib is decreased, and even those children not immunized will be protected. This phenomenon could explain the finding of only one Hib nasopharyngeal carrier was found among the children enrolled in the trial. Another possible explanation for this phenomenon is the finding that a large number of children (26.07\%) developed anti-PRP titres even higher than $5 \mu \mathrm{g} / \mathrm{ml}$. The serological correlations of protection from Hib carriage are not well understood however, a high serum antibody concentration seems to be needed to prevent colonization, higher than the concentration needed for preventing invasive disease (Takala et al. 1991).

This study shows that the Cuban children had high anti-PRP concentrations and provides strong evidence that children in some developing countries acquire natural active immunity to Hib at an early age (Tastan et al. 2000, Puliyel et al. 2001, Clemens et al. 2003). These results support the recommendation of the World Health
Organization that the strategy of administering Hib vaccine to all children under 5 years old must be considered only in those countries which can afforded it without to diverting resources from essential infants vaccination programs (WHO 1998).

Natural immunity to Hib seems to be different among children from one country to another, depending on geographical, genetic, and social factors. The high natural immunity may be accounted for by high endemicity of Hib in some countries, and over time, it is possible that the ability to mount an elevated response against the bacteria could be selected in the populations. We suggest that each country should investigate the natural immunity in children between 1-5 years of age, before deciding whether to introduce Hib vaccine in routine immunization programmes in children in this age group.

\section{REFERENCES}

Acharya D, Bhave S, Joshi V, Bavdekar A, Pandit A 1997. Haemophilus influenzae type $\mathrm{b}$ in India: need and timing, immunogenicity and tolerance. Indian Pediatr 34: 9-15.

Bradshaw M, Scheerson R, Parke J, Robbins J 1971 Bacterial antigens cross reactive with capsular polysaccharide of Haemophilus influenzae type b. Lancet 1: 1095-1096.

Clemens S, Azevedo T, Homma A 2003. Feasibility study of the immunogenicity and safety of a novel DTPw/Hib (PRPT) Brazilian combination compared to a licensed vaccine in healthy children at 2, 4, and 6 months of age. Rev Soc Bras Med Trop 36: 321-330.

Dickinson F, Pérez A, Galindo M, Quintana I 2001. Impact of vaccination against Haemophilus influenzae type b in Cuba. Rev Panam Salud Publica 10: 169-173.

Fernández J, Balter S, Feris J, Gómez E, Garib Z, Castellanos P, Sánchez J 2000. Randomized trial of the immunogenicity of fraccional dose regimens of PRP-T Haemophilus influenzae type b conjugate vaccine. Am J Trop Med Hyg 62: 485-490.

Kayhty H 1998. Immunogenicity assay and surrogate markers to predict vaccine efficacy. In F Brown, S Plotkin (eds), Preclinical and Clinical Development of New Vaccines, Dev Biol Stand Basel, Karger, Vol. 95, p. 175-180.

Kaythy H, Eskola J, Peltola H, Stout M, Samuelson J, Gordon L 1987. Immunogenicity in infants of a vaccine composed of Haemophilus influenzae type b capsular polysaccharide mixed DPT or conjugated to diphtheria toxoid. J Infect Dis 155: 100-106.

Kaythy H, Eskola J, Peltola H, Ronnberg P, Kela E, Keranko V, Saarinen L 1991. Antibody response to four Haemophilus influenzae type b conjugate vaccines. Am J Dis Child 145: 223-227.

Kaythy H, Eskola J, Peltola H, Saarinen L, Makela PH 1992. High antibody responses to booster doses of either Haemophilus influenzae type b capsular polysaccharide or conjugated vaccine after primary immunization with conjugated vaccines. J Infect Dis 165 (Suppl. 1): S165-S166.

Phipps D, West J, Eby R, Koster M, Madore D, Kuataert S 1990. An ELISA employing a Haemophilus influenzae type b oloigosaccharide; human serum albumin conjugate correlates with the radioantigen binding assay. J Immunol Methods 135: 121-128.

Puliyel J, Agarwal K, Abass F 2001. Natural immunity to Haemophilus influenzae type $\mathrm{b}$ in infancy in Indian children. Vaccine 19: 4592-4594.

Schneerson R, Robbins JB 1995. Induction of serum Haemophilus influenzae type b capsular antibodies in adult 
volunteers fed cross-reacting Escherichia coli 075: K100:H5. New England J Med 292: 1093-1096.

Takala AK, Eskola J, Leimonen M, Kaythy H, Nissinen A, Pekkanen E, Makela PH 1991. Reduction of oropharyngeal carriage of Haemophilus influenzae type b (Hib) in children immunized with an Hib conjugated vaccine. J Infect Dis 164: 982-986.
Tastan Y, Alikasifoglu M, Ilter O, Erginoz, Arvas A, Yuksal D, Turkcu F, Badur S 2000. Natural immunity to Haemophilus influenzae type $\mathrm{b}$ among healthy children in Istambul, Turkey. Indian Pediatrics 37: 414-417.

WHO 1998. Global Programme for Vaccines and Immunisation. The WHO position paper on Haemophilus influenzae type b conjugate vaccines. WER 73: 64-68. 
